\title{
Radiopharmaceutical Treatment of Pheochromocytomas
}

\author{
JAMES C. SISSON \\ University of Michigan Health System, Ann Arbor, Michigan 48109-0028, USA
}

\begin{abstract}
Malignant pheochromocytomas, a group of tumors that include metastatic paragangliomas, often produce hypertension and episodic symptoms from secretion of norepinephrine and sometimes epinephrine. In addition, the tumors usually manifest progressive metastases. Blockade of alpha and beta adrenergic receptors will control blood pressure and symptoms, but reduction of the malignancy has been difficult to achieve. Meta-iodobenzylguanidine (MIBG) follows the pathways of norepinephrine and, when labeled with 131-I, will concentrate sufficiently in the pheochromocytoma to impart therapeutic radiation. More than 100 patients have received treatment with 131-I-labeled MIBG at multiple medical centers. Individual doses were 3.7 to $18.5 \mathrm{GBq}(100$ to $>500 \mathrm{mCi})$, and many patients received several doses separated by a few months. Partial remissions, recorded as decreased tumor presence and tumor function, have been observed in one-third or more of the treated patients. However, complete remissions are rare, and recurrence/progression within two years is the rule. Toxicity was generally modest and temporary. Subsequent chemotherapy increased the benefits attained by 131-I MIBG, but, in a small series of patients, this combination did not further change the outcome. Nevertheless, selective radiation from 131-I MIBG or a similar radiopharmaceutical could play a valuable role in treatments that combine several types of attacks on this recalcitrant malignancy.
\end{abstract}

KEYWORDS: pheochromocytoma; paraganglioma; malignancy; metaiodobenzylguanidine

\section{INTRODUCTION}

Although pheochromocytomas are rare neoplasms and constitute only about $0.1 \%$ of the causes of hypertension, ${ }^{1}$ these tumors derive importance from the sometimes dramatic clinical presentations resulting from secreted neurohormones, and by often being cured by surgical excision. Included in

Address for correspondence: James C. Sisson, M.D., Hospital B1 505G, University of Michigan Health System, Ann Arbor, MI 48109-0028. Voice: 734-936-5387; fax: 734-936-8182.

jsisson@umich.edu

Ann. N.Y. Acad. Sci. 970: 54-60 (2002). () 2002 New York Academy of Sciences. 
the category of pheochromocytomas are the paragangliomas, those tumors with the same potentials but arising from adrenergic tissues outside of the adrenal medulla.

About $10-15 \%$ of pheochromocytomas are metastatic, ${ }^{2}$ and, because of anatomic dispersal, cannot be fully resected. For these carcinomas, therapy beyond surgical excision must be sought. Pharmacologic blockade of alpha and beta adrenergic receptors will usually relieve the hypertension and symptoms arising from the effects of the neurohormones, norepinephrine and epinephrine, but do not impede neoplastic growth. Chemotherapy, consisting of cylophosphamide, dacarbazine and vincristine, has produced one complete and several partial remissions ${ }^{3}$; however, the program requires considerable skill and time to administer and is not well-tolerated by some patients. External beam radiation can lessen pain caused by individual tumors, but the courses of malignant pheochromocytomas are unaltered. The radiopharmaceutical, 131-I-labeled meta-iodobenzylguanidine (131-I-MIBG), was found, during diagnostic study, to concentrate in about $85-90 \%$ of pheochromocytomas, including metastases. ${ }^{4}$ From quantified scintigraphic data, the potential for delivering selective radiation to the unresectable tumors was recognized. ${ }^{5}$

Although classified as an analogue of guanethidine, MIBG (FIG. 1) follows the kinetic pathways of norepinephrine. 131-I-labled MIBG enters adrenergic cells via the uptake-1 pathway and is sequestered by the storage granules. ${ }^{6}$ It is released from the cells by exocytosis ${ }^{7}$ and, to some extent, by reversal of the uptake pathway. The agent appears not to bind to adrenergic receptors and thus has no direct pharmacologic action ${ }^{8}$; however, in large quantities, it may exhibit a tyramine-like effect by displacing norepinephrine from nerve terminals. ${ }^{7}$ When concentrated and retained in substantial amounts by the tumors, the radiation imparted by the 131-I label can be therapeutic. About $90 \%$ of the radiation will be derived from the beta particle, from which most of the energy is deposited along a path of $1 \mathrm{~mm}$. Thus, the radiation from 131-I MIBG is largely confined to targeted pheochromocytomas. The common therapeutic prescriptions have been 3.7-7.4 GBq (100$200 \mathrm{mCi}) .{ }^{9}$ A concentration of $131-\mathrm{I}$ MIBG of $0.1 \%$ of the administered radioactivity per gram of tumor and an effective half life in the tumor of 3 days were reasonable estimates from diagnostic data of some patients; in this circumstance administration of $100 \mathrm{mCi}$ to a patient will impart 4000-5000 cGy (rad) to the pheochromocytomas. Measurements recorded $13-82 \mathrm{cGy} / \mathrm{mCi}$ for tumors in a number of patients, ${ }^{10}$ and $>5000 \mathrm{cGy}$ can be attained with multiple treatments in selected patients. ${ }^{11}$ The radiopharmaceutical is also concentrated in normal adrenergic tissues, particularly neuron terminals and the adrenal medulla, but therapeutic doses of 131-I MIBG have not produced observable changes in these organs. The serious toxic effects have been largely confined to depression of bone marrow function. 

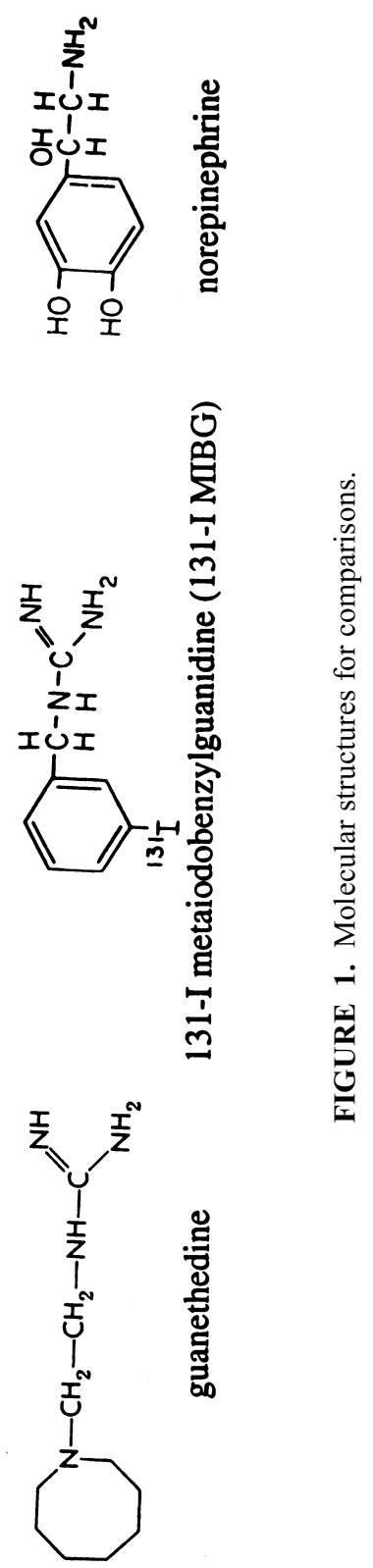
TABLE 1. Results of treatment of pheochromocytoma with 131-I-labeled MIBG

\begin{tabular}{|c|c|c|c|c|c|}
\hline & $\begin{array}{c}\text { No. } \\
\text { of patients }\end{array}$ & $\begin{array}{l}\text { Complete } \\
\text { remission }^{a} \\
\quad(\%)\end{array}$ & $\begin{array}{l}\text { Partial } \\
\text { remission }^{a} \\
\quad(\%)\end{array}$ & $\begin{array}{l}\text { Little or } \\
\text { no change } \\
(\%)\end{array}$ & $\begin{array}{c}\text { Progression } \\
\text { of disease } \\
(\%)\end{array}$ \\
\hline \multicolumn{6}{|l|}{ Literature review ${ }^{9}$} \\
\hline Tumor presence ${ }^{a}$ & 116 & 4 & 26 & 57 & 13 \\
\hline Tumor function $^{a}$ & 96 & 13 & 32 & 45 & 10 \\
\hline \multicolumn{6}{|l|}{ Literature review $^{12}$} \\
\hline Tumor presence ${ }^{a}$ & 137 & 6 & 18 & 55 & 21 \\
\hline Tumor function ${ }^{a}$ & 120 & & $39^{b}$ & & \\
\hline \multicolumn{6}{|c|}{ University ofMichigan $^{c}$} \\
\hline Tumor presence ${ }^{a}$ & 6 & 0 & 33 & 33 & 33 \\
\hline Tumor function ${ }^{a}$ & 6 & 17 & 17 & 33 & 33 \\
\hline
\end{tabular}

${ }^{a}$ See text for definitions of remission and tumor presence and function.

${ }^{b}$ Includes partial and complete remission.

${ }^{c}$ Changes observed before chemotherapy was given. ${ }^{11}$

\section{RESULTS FROM TREATMENTS WITH 131-I MIBG}

In a review of the literature in 1997 (TABLE 1), Loh et al. found reports covering 116 patients treated for malignant/unresectable pheochromocytomas by 131-I MIBG; the authors added 3 patients of their own. ${ }^{9}$ Most treatments were of 3.7-7.4 GBq that were given multiple times separated by several months to individual patients. A subsequent review by Troncone and Rufini in $1999^{12}$ increased the total to 137 patients including 28 treated at the University of Michigan up to that time (TABLE 1). ${ }^{10}$ In single infusions of 131-I MIBG, more than $11.1 \mathrm{GBq}$ have been administered, ${ }^{11}$ and one patient received more than 18.5 GBq. ${ }^{9}$ Responses to the therapies were defined in terms of tumor presence (determined by CT, 131-I MIBG scintigraphy and/ or bone scintigraphy) and tumor function (assayed by rates of urinary excretion of catecholamines and/or catecholamine metabolites). Some of the patients in the published papers did not have clearly defined tumor presence or function so that the numbers of patients in each index did not regularly equal the total number of patients treated.

Complete remissions (disappearance of all evidence of tumor presence and function) were uncommon, and some of those so classified exhibited small tumors seen only by MIBG scintigraphy ${ }^{13-15}$ and/or had little or no elevations in the indices of tumor function. ${ }^{9,15}$ Partial remissions (reduction of tumor presence and/or tumor function by half or more) occurred in 18-39\% of patients giving complete plus partial remission rates of $24-45 \%$. There was 
no obvious relationship between remission and administered dose. Relapses and/or progression of disease within two years were the rule.

Stable disease was reported for 33-60\% of patients after treatment with 131-I MIBG. Although it is tempting to attribute stability to irradiation from 131-I MIBG, such carcinomas have often run indolent courses and, in the past, as many as $17 \%$ of patients have survived more than 20 years. $^{2}$

Toxicity from 131-I MIBG was modest for most treated patients. Most vulnerable was the bone marrow; one patient died from pancytopenia. ${ }^{16}$ Nausea and vomiting, at times severe for a few days, was common. ${ }^{9-12}$ Liver dysfunction followed treatments of patients with liver metastases. ${ }^{9}$ Exacerbation of manifestations of excessive catecholamines appeared in some subjects. ${ }^{9,12}$ Hypothyroidism, presumably from thyroid sequestration of 131-I iodide metabolized from the 131-I MIBG, has occasionally occurred despite preventive treatments with stable iodides. ${ }^{9,10,12}$

Added to TABLE 1 are data from the latest experience with six patients at the University of Michigan. ${ }^{11}$ Following three treatments with 131-I MIBG at 3-month intervals, there were partial remissions in tumor presence for two patients; one patient whose functional abnormality was modest had a complete remission and another had a partial remission in tumor function. Chemotherapy (cyclophosphamide, dacarbazine and vincristine in cycles over one year) was associated with further diminutions in tumor presence and function. However, toxicities - neutropenia, anemia and neuropathy-from the chemotherapy required reductions in doses of individual agents. In this small group of patients receiving these combined modalities, benefits from the additional chemotherapy were modest but demonstrated that attacks on malignant pheochromocytomas in multiple ways may be an effective approach to these resistant tumors.

\section{DISCUSSION}

131-I-labeled MIBG is selectively concentrated in many malignant pheochromocytomas to a level enabling therapeutic radiation of $>5000$ and possibly 20,000 cGy from multiple doses of this radiopharmaceutical. However, complete remissions have been rare, and the patients who have developed partial remissions in tumor presence and/or function usually exhibit relapses within 2 years. Probably the carcinomas consist of cells with varying affinities for 131-I MIBG, and, therefore the irradiation by 131-I is unevenly distributed within the tumors.

Although the initial experience with multiple-modality treatment (that is, adding a chemotherapy program to treatments with 131-I MIBG) did not demonstrate striking results, there was an additive effect. Possibly a third type of treatment, such as adding autologous bone marrow transplantation af- 
ter higher doses of 131-I MIBG and more intensive chemotherapy, will produce better results.

\section{SUMMARY}

Malignant pheochromocytomas have resisted therapies. Selective irradiation from multiple doses of 131-I MIBG reduced tumor presence and function, resulting in remissions, partial and complete, in $24-45 \%$ of patients. Because most patients have unyielding tumors and because relapses are common in the responsive pheochromocytomas, additional treatments must be sought. Multi-modality therapies may improve the outcomes.

\section{ACKNOWLEDGMENT}

The author is indebted to Ms. Carol Kruise for help in typing.

\section{REFERENCES}

1. Manger, W.M. \& R.W. Gifford, JR. 1996. In Clinical and Experimental Pheochromocytoma, 2nd ed. W.M. Manger \& R.W. Gifford, Jr. Eds.: 4. Blackwell Science, Inc. Cambridge, MA..

2. Remine W.H., G.C. Chong, J.A. Van Heerden, et al. 1974. Current management of pheochromocytoma. Ann. Surg. 30: 740-747.

3. Averbuch, S.D., C.S. Steakley, R.C. Young, et al. 1988. Malignant pheochromocytoma: effective treatment with a combination of cyclophosphamide, vincristine, and dacarbazine. Ann. Intern. Med. 109: 267-273.

4. Shapiro, B., J.E. Copp, J.C. Sisson, et al. 1985. Iodine-131 metaiodobenzylguanidine for the locating of suspected pheochromocytoma: experience in 400 cases. J. Nucl. Med. 26: 576-585.

5. Sisson, J.C., B. Shapiro, W.H. Beierwaltes, et al. 1984. Radiopharmaceutical treatment of malignant pheochromocytoma. J. Nucl. Med. 25: 197-206.

6. JAQUES, S., M.C. ToBES \& J.C. SisSON. 1987. Sodium dependency of uptake of norepinephrine and $\mathrm{m}$-iodobenzylguanidine into cultured human pheochromocytoma cells: evidence for uptake-one. Cancer Res. 47: 3920-3928.

7. Sisson J.C., D.M. Weiland, P. Sherman, et al. 1987 Metaiodobenzylguanidine as an index of the adrenergic nervous system intergrity and function. J. Nucl. Med. 28: 1620-1624.

8. Wieland, D.M., L.E. Brown, M.C. Tobes, et al. 1981. Imagine the primate adrenal medullae with $\left[{ }^{123} \mathrm{I}\right]$ and $\left[{ }^{131} \mathrm{I}\right]$ meta-iodobenzylguanidine: concise communication. J. Nucl. Med. 22: 358-364.

9. Loh, K.C., P.A. Fitzgerald, K.K. Matthay, et al. 1997. The treatment of malignant pheochromocytoma with iodine-131 metaiodobenzylguanidine 
(131I-MIBG): a comprehensive review of 116 reported patients. J. Endocrinol.Invest. 20: 648-658.

10. Shapiro, B., J.C. Sisson, D.M. Wieland, et al. 1992. Radiopharmaceutical therapy of malignant pheochromocytoma with $\left[{ }^{131} \mathrm{I}\right]$ metaiodobenzylguanidine: results from ten years of experience. J. Nucl. Biol. Med. 35: 267-276.

11. Sisson J.C., B. Shapiro, B.S. Shulkin, et al. 1999. Treatment of malignant pheochromocytomas with 131-I metaiodobenzylguanidine and chemotherapy. Am. J. Clin. Oncol. 22: 364-370.

12. TRoncone L. \& V. Rufini. 1999. Nuclear medicine therapy of pheochromocytoma and paraganglioma. Quart. J. Med. 43: 344-355.

13. Schvartz, C., C. Gibold, B. Vuillemin, et al. 1992. Results of $\left[{ }^{131} \mathrm{I}\right]$ metaiodobenzylguanidine therapy administered to three patients with malignant pheochromocytoma. J. Nucl. Biol. Med. 35: 305-307.

14. Troncone, L., V. Rufini, P. Montemaggi, et al. 1990. The diagnostic and therapeutic utility of radioiodinated metaiodobenzylguanidine. Eur. J. Nucl. Med. 16: 325-335.

15. Troncone, L., V. Rufini, M.S. Daldone, et al. 1991. [ $\left.{ }^{131} \mathrm{I}\right]$ metaiodobenzylguanidine treatment of malignant pheochromocytoma: experience of the Rome group. J. Nucl. Biol. Med. 35: 295-299.

16. KrempF, M., J. Lumbroso, R. MoreX., et al. 1991. Use of m- $\left[{ }^{131} \mathrm{I}\right]$ iodobenzylguanidine in the treatment of malignant pheochromocytoma. J. Clin. Endocrinol. Metab. 72: 455-461. 